\title{
Development and application of integrative jumbo for deep hole sampling
}

\author{
WANG Gang ${ }^{1,2}$, YANG Xin-xiang ${ }^{2 *}$, XIAO Wei², WU Meng-meng ${ }^{2}$
}

(1. Key Laboratory of Ministry of Education for Mine Disaster Prevention and Control, Shandong

University of Science and Technology, Shandong Qingdao 266590; 2. Shandong University of Science and

Technology, College of Mining and Safety Engineering, Shandong Qingdao 266590)

\begin{abstract}
According to the fact that the coal seam in our country is soft and the traditional sampling equipment is difficult to achieve the required sampling depth, speed, integrity and so on, integrative jumbo of deep hole sampling is designed and built, this jumbo has the properties of large power and small volume, can realize lateral and distant drilling through obstacle, it also has functions of automatic locking positioning, sampling while drilling and positional sampling. The field test of the integrative jumbo showed that the real sampling time of integrative jumbo is just 1 to 2 minutes, providing effective technical means for confirming the lost gas of coal seam. The total weight of coal samples obtained by the test is generally higher than $1000 \mathrm{~g}$, also the weight of coal samples with greater than $1 \mathrm{~mm}$ diameter exceed $500 \mathrm{~g}$, and to a maximum of $2690 \mathrm{~g}$. The sampling depth and initial desorption velocity have been more improved by integrative jumbo for deep hole sampling than that with traditional sampling method, it can also completely meet the calculation accuracy of initial desorption velocity.
\end{abstract}

Keyword: coal; deep hole; sampling; integrative jumbo; gas content

\section{Introduction}

Gas content determination of coal seam can be divided into direct and indirect methods. Direct method is to collect coal samples directly for gas desorption and loss measure to determine gas content $[1,2]$. This method has the advantage in that gas content can be directly determined and it can avoid the indirect determination of error measurement of multiple parameters. The key link of the direct determination of gas content in coal seam is well sampling, the sampling quality is directly related to the accuracy of determination of coal seam gas content. The key to the success of coal seam sampling lies in coal sample integrity and shelf character and rapidity [3].

The current common methods of direct sampling including Circular Pipe Wind Discharge Dust Method, Hydraulic Discharge Dust Sampling Method [4], Coal Core Sampler Sampling Method [5] and Twist Spiral Drill Pipe Discharge Dust Sampling Method [6]. Wind Discharge Dust Method has the advantage of sampling time is short, sampling process is simple. Due to the effect of wind, there are little likelihood of sticking and no accumulation of coal duff in the borehole, but its biggest drawback is that the drilling process is difficult to control. Compared with Circular Pipe Wind Discharge Dust Method, Coal Core Sampler Sampling Method has better performance in fixed-point sampling, it is mainly used in hard coal seam bedding or wear layer core upwards, but the coal core sampler sampling time is too long, most of the free gas in the process of sampling is lost which affected the gas content measurement result, while Coal Core Sampler Sampling Method still exists defects such as field construction is not easy to operation. The essence of Twist Spiral Drill Pipe Discharge Dust Sampling

* Corresponding author. Tel.: +86 18765923669 .

E-mail address: jasonbox2016@hotmail.com (X. Yang). 
Method is the swirl pulverized coal will be discharged from the coal wall or the bottom of the hole in the process of drill pipe rotation. Twist Spiral Drill Pipe Discharge Dust Sampling Method is simple, the operation is not complicated, but its own defects are as follows: deep sampling construction is difficult, when met the phenomenon of down hole, drill pipe is difficult to remove; the drilling rate of drill pipe is hard to control, sampling can be affected if it is too low, and sticking phenomenon appears easily if it is too high; it is easy to take pulverized coal of different drilling depth out in the process of sampling, thus affecting the measurement of gas content. According to the fact that the coal seam in our country is soft and the traditional sampling equipment is difficult to achieve the required sampling depth, speed, integrity and so on, in order to determine coal seam gas content more accurately and more quickly, the deep coal borehole sampling equipment is studied, and it is gradually optimized through the field test.

\section{Sampling equipment and process design requirements}

The design of the sampling drilling tools and the research of sampling process are two key technologies to guarantee access to effective coal samples, the sampling results can be affected if the design and processing of the sampling drilling tools are unreasonable, and even the coal sample can't be got. Improper sampling process may cause phenomenon of burying and seizing drilling which lead to the extension of sampling time, the coal sample can't be got or the nature change of the taken coal samples. Therefore, sampling techniques and equipment should be cooperated.

The design and process of sampling equipment put forward higher requirements in the study of sampling equipment and process, these requirements includes:

- Sampling in the designated depths;

- Single hole sampling;

- The damage of coal sample during the process of collection and transmission should be as small as possible;

- Coal samples should be sent as soon as possible;

- The coal samples can't be mixed during the process of collection and transmission;

- Obtaining coal samples while drilling;

- Duff can be coal samples;

- Sampling equipment should be matched with existing drilling equipment as far as possible;

- With high reliability and operability;

- Easy to maintain;

- Compliance with mine safety requirements.

\section{Design scheme of the integrative jumbo for deep hole sampling}

\subsection{The principle of structure}

For sampling equipment and process design requirements, combined with mining practice, independently developed the integrative jumbo for deep hole sampling, the jumbo is mainly composed of host, column, cross beam, electrical operating station, lifting device, ontology frame assembly, hydraulic benchboard, vacuum generator, chassis, operation platform, tank component and so on. Structure diagram of the jumbo shown in Figure 1. 

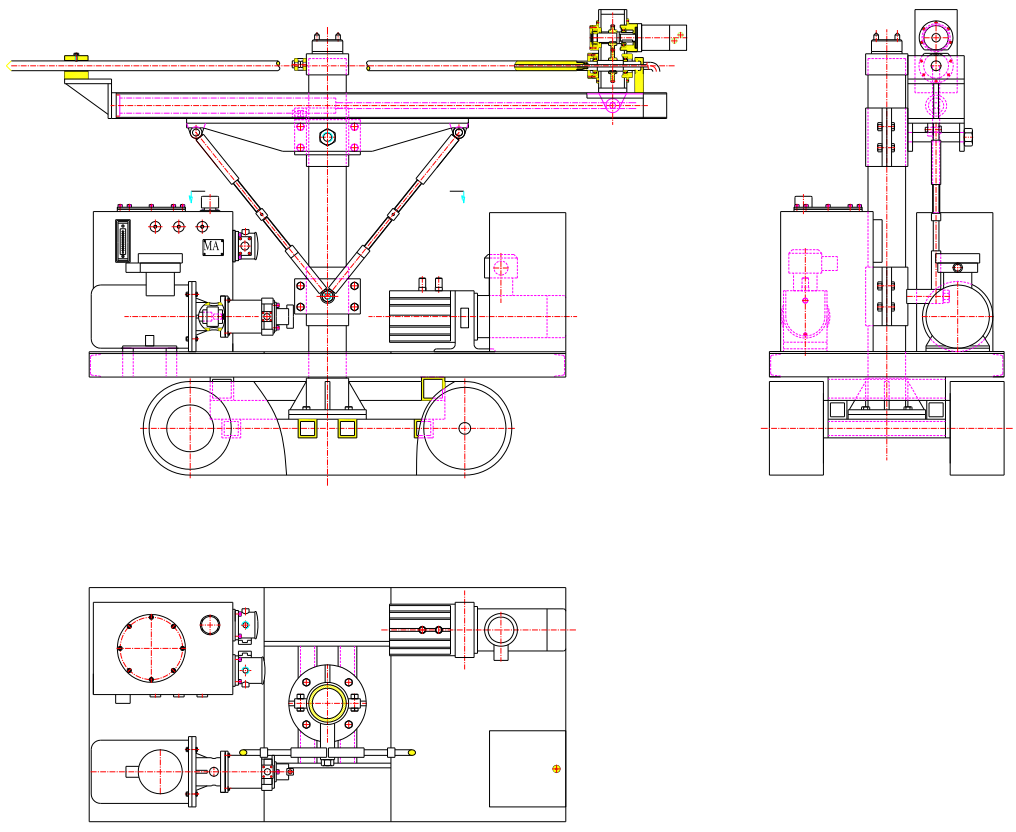

Figure 1 Structure diagram shown of the integrative jumbo for deep hole sampling

Jumbo travel agencies using gas-powered motor and gear pump output device was composed by track assembly, driving wheel groups, uniform support, underframe and so on. Because the jumbo need fixed support during drilling, column is divided into the upper and the lower two parts. In order to avoid the collision with the top of the road and rollover of the jumbo, the lower part can be removed to reduce the height of jumbo while walking. To increase the stability of jumbo when operating, the oil cylinder in the column can make jumbo jacking the top of the roadway in advance. Host has an angle adjustment mechanism and it can adjust the angle of horizontal direction according to the job requirements. Jumbo lifting device was composed by a parallelogram, and has the advantages of compact structure, large lifting distance, and can meet the demand for different height of drilling for jumbo operators.

Considering the vacuum pump has the large volume, high prices, and it is inconvenient to use and easy to wear and other shortcomings [7], therefore, the design uses a vacuum generator to replace pump. The jetting vacuum generator is a kind of pneumatic vacuum components which use positive pressure air supply in the production of negative pressure, its structure shown in Figure 2. According to the Bernoulli equation in fluid mechanics, when the gas flow rate is increased, pressure could be reduced, when the flow rate is increased to a certain value, the pressure could be smaller than an atmospheric pressure, and therefore, increasing the gas flow method can be used to obtain a certain degree of vacuum. System response time is an important parameter reflecting the speed of the vacuum extraction process, it refers to the process time of the vacuum degree of the vessel and the vacuum pump from zero to a certain vacuum degree, and it is also one of the key performance indicators of jet vacuum generator in applications. Gas consumption is an important indicator to measure the pneumatic system or pneumatic components of the economy, can be obtained through the integral of supply flow $q$ in a complete working cycle period t, can also be obtained from the product of average supply flow size $q$ and $t[8,9]$. 


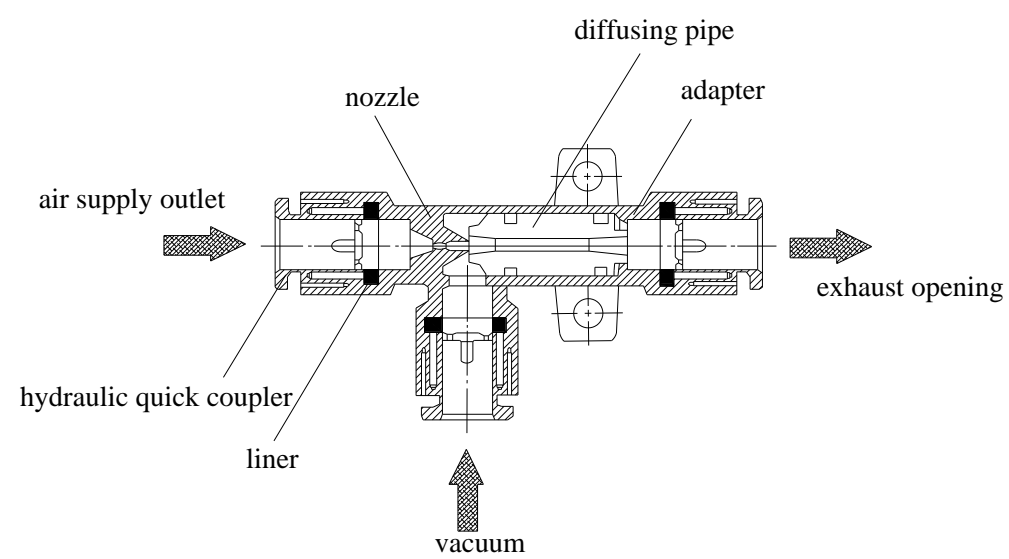

Figure 2 Structure diagram of the jet vacuum generator

Key performance indicators of jet vacuum generator can be attributed to: ultimate vacuum, response time, air consumption. Key performance parameters of the sampling jumbo jet vacuum generator system were shown in Table 1.

Table 1 Main performance parameters of jet vacuum generator

\begin{tabular}{|c|c|}
\hline Performance parameters & Jet vacuum generator \\
\hline Supply flow $\left(10^{-3} \mathrm{~m}^{3} / \mathrm{min}\right)$ & 50 \\
\hline Supply pressure $(\mathrm{MPa})$ & 0.4 \\
\hline Response time (s) & 4.8 \\
\hline Ultimate vacuum (KPa) & 91 \\
\hline $\begin{array}{c}\text { Gas consumption of vacuum } \\
\text { reached } 80 \mathrm{KPa}(10-3 \mathrm{~m} 3)\end{array}$ \\
\hline
\end{tabular}

\subsection{Equipment characteristics and performance}

\section{parameters of whole machine}

High safety: using compressed air as power source, using safely.

High power and small volume: the diameter and depth of hole are in a leading position in the domestic. In the drilling construction of any hard and soft medium, bit cutting terminal always stay more than $6 \mathrm{kw}$ power output. The jumbo is small and can walk freely within the minimum 1 meter of the roadway.

Lateral distance across obstacles punch drill: rail can be $\pm 90^{\circ}$ rotation meanwhile rail with telescopic function and can cross obstacles drilling construction.

Automatic locking and positioning: lifting device automatic locking position, saved drilling solid time greatly and improved the stability of the rig. At the same time the fixing devices adopts advanced low pressure pneumatic alarm and minimize the potential safety hazards effectively.

Highly reliable lubrication system: jumbo lubrication system with high reliability and effectively extending the life of the equipment.

Table 2 Test performance parameters of sampling Drill

\begin{tabular}{|c|c|}
\hline Test parameters & Sampling jumbo \\
\hline Apply pressure (MPa) & $0.4-0.63$ \\
\hline Rated pressure (MPa) & 0.5 \\
\hline Rated torque (N·m) & 400 \\
\hline Rated speed (r/min) & 125 \\
\hline Load consumption (m³min) & 10 \\
\hline Maximum output power (kW) & 6 \\
\hline Propulsion (kN) & 1300 \\
\hline Advance stroke (mm) & $1200-2000$ \\
\hline Horizontal drilling height (mm) & \pm 20 \\
\hline Borehole inclination $\left(^{\circ}\right)$ & \pm 90 \\
\hline Horizontal rotation angle $\left(^{\circ}\right)$ & 18 \\
\hline Gradeability $\left({ }^{\circ}\right)$ & \\
\hline
\end{tabular}

\subsection{Supporting tools and applications}

The integrative jumbo for deep hole sampling can simply replace the bushing to support the use with a variety of screw drill and geological drill, also specifically designed for the jumbo with high efficient spiral drill pipe, the drill pipe with square shank, spring 
bayonet to connect drill pipe quickly. Application of the fixing structure to ensure concentricity after multi-section pipe connections is the first time in domestic, using a special custom material processing a drill pipe with features like steep-lead, superior performance of coaxial, spirochetes wide, chip removal faster when the drill pipe drilling and the drilling speed is quick, and it is suitable for the operation of coal seam

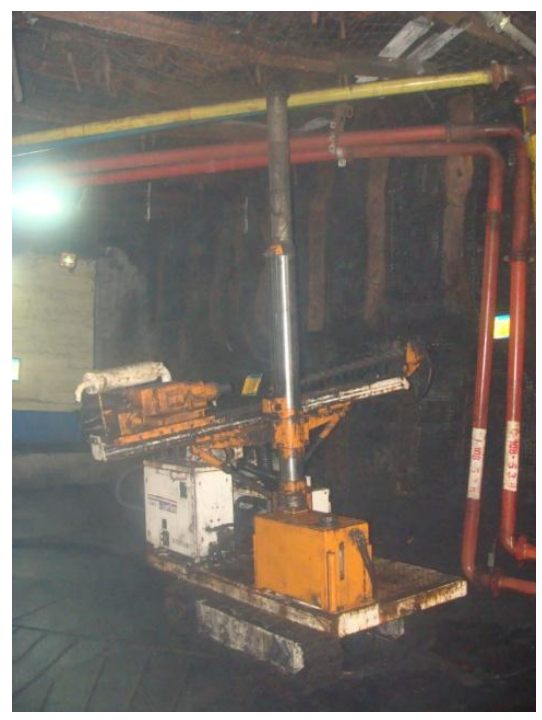

Figure 3 The test of the integrative jumbo for deep hole sampling

As shown in Figure 4, the traditional hand drilling compare with the integrative jumbo for deep hole sampling method was adopted for the test in the field to sampling about sampling results.

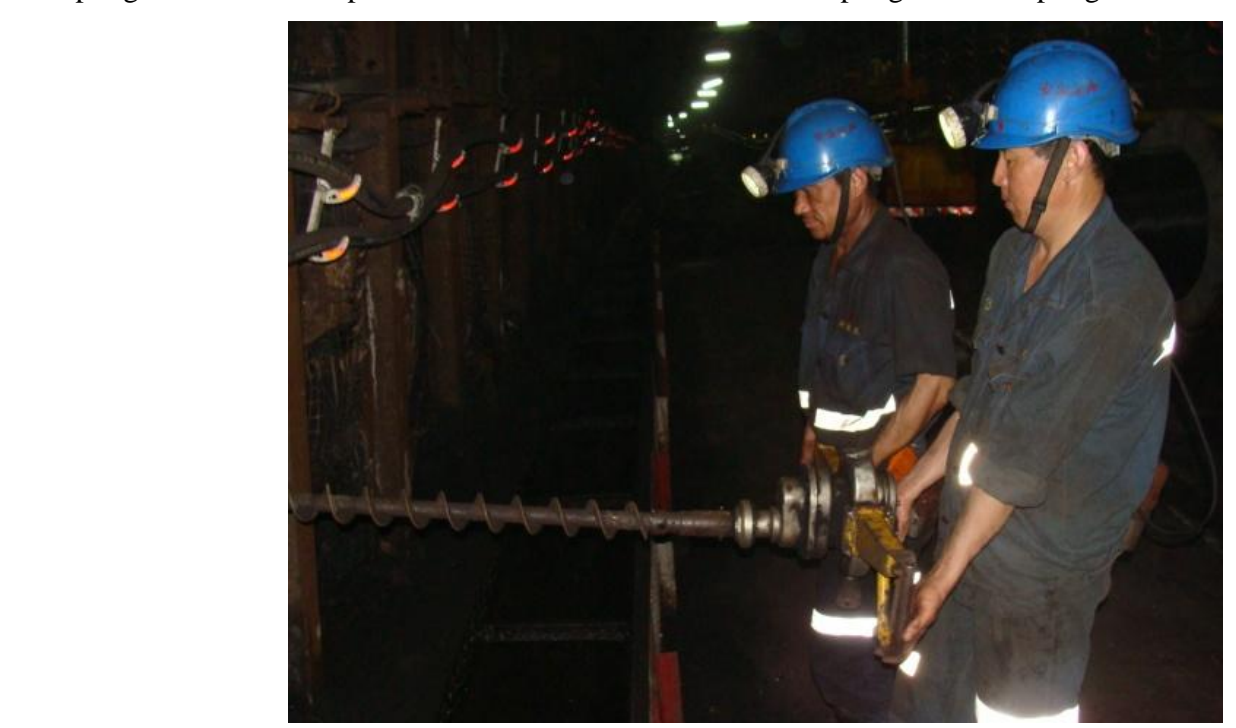

Figure 4 Manual drilling sampling test

New sampling techniques and equipment in order to quickly and efficiently collect coal samples for gas with high gas content and fragile hole.

\section{Field Test}

Field commissioning and testing were conducted after the successful development of the integrative jumbo for deep hole sampling. As shown in Figure 3, the air pressure of jumbo was an average about $0.5 \mathrm{MPa}$, the use of the bit diameter was $87.6 \mathrm{~mm}$, drill pipe diameter was $76.6 \mathrm{~mm}$.

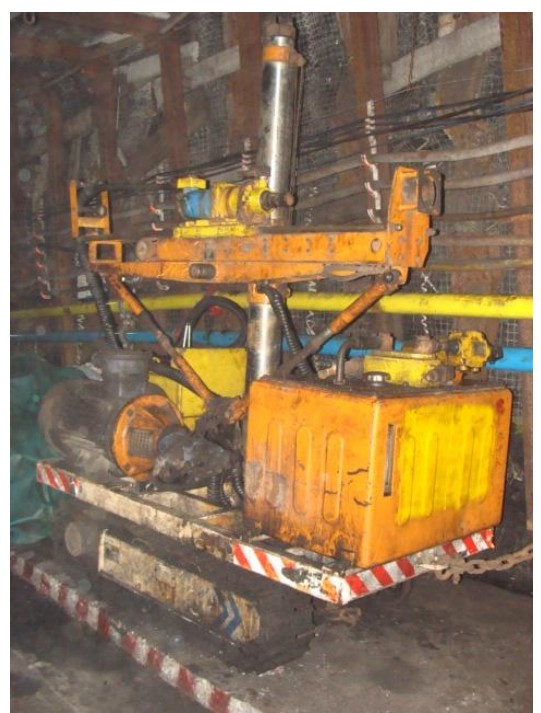

desorption tests, accurate determination of the initial velocity of gas desorption provided a reliable technical 
data to predict coal and gas outburst by gas content method. In the course of this field trial, mainly examines the weight, particle size and initial desorption of coal sample.

(1) Coal particle size and weight

the particle size and weight of the coal samples obtained during the test are shown in Table 3, as can be seen from the table, the total weight of coal samples obtained by the test were generally higher than $1000 \mathrm{~g}$, the maximum weight of coal samples obtained when the coal drilling depth was 25 , the weight of coal sample was $6353 \mathrm{~g}$; greater than $1 \mathrm{~mm}$ in diameter of coal sample generally in more than $500 \mathrm{~g}$ in weight, up for $2690 \mathrm{~g}$. When measuring gas content, the weight of coal samples which diameter is larger than $1 \mathrm{~mm}$ is at around $200 \mathrm{~g}$ [10,11], therefore, the effectively coal samples got by the integrative jumbo for deep hole sampling coincidence the requirements of the gas content method experiment, in full compliance with the needs of the experimental determination of gas.

Table 3 The analysis of field test size

\begin{tabular}{|c|c|c|c|c|c|c|c|c|c|}
\hline $\begin{array}{l}\text { Serial } \\
\text { number }\end{array}$ & $\begin{array}{l}\text { Sampling } \\
\text { depth/m }\end{array}$ & $\begin{array}{l}\text { Drilling } \\
\text { method }\end{array}$ & $\begin{array}{c}\text { Total } \\
\text { weight } \\
\text { /g }\end{array}$ & $\begin{array}{c}>1 \mathrm{~mm} \\
\text { Particle } \\
\text { size } \\
\text { weight/g }\end{array}$ & $\begin{array}{c}>1 \mathrm{~mm} \\
\text { Particle } \\
\text { size } \\
\text { ratio/\% }\end{array}$ & $\begin{array}{c}1-3 \mathrm{~mm} \\
\text { Particle } \\
\text { size } \\
\text { weight/g }\end{array}$ & $\begin{array}{c}1-3 \mathrm{~mm} \\
\text { Particle } \\
\text { size } \\
\text { ratio/\% }\end{array}$ & $\begin{array}{c}>3 \mathrm{~mm} \\
\text { Particle } \\
\text { size } \\
\text { weight/g }\end{array}$ & $\begin{array}{c}>3 \mathrm{~mm} \\
\text { Particle } \\
\text { size } \\
\text { ratio/\% }\end{array}$ \\
\hline 1 & $15-16.5$ & $\begin{array}{l}\text { Traditional } \\
\text { sampling }\end{array}$ & 573 & 332 & 57.94 & 128 & 22.34 & 113 & 19.72 \\
\hline 2 & $22.5-25$ & $\begin{array}{l}\text { Traditional } \\
\text { sampling }\end{array}$ & 770 & 190 & 24.68 & 350 & 45.45 & 230 & 29.87 \\
\hline 3 & $30-31.5$ & $\begin{array}{l}\text { Traditional } \\
\text { sampling }\end{array}$ & 1532 & 756 & 49.35 & 387 & 25.26 & 389 & 25.39 \\
\hline 4 & $15-16.5$ & $\begin{array}{c}\text { Drill } \\
\text { sampling }\end{array}$ & 1560 & 1004 & 64.36 & 381 & 24.42 & 175 & 11.22 \\
\hline 5 & $22.5-25$ & $\begin{array}{c}\text { Drill } \\
\text { sampling }\end{array}$ & 6353 & 3666 & 57.71 & 1629 & 25.64 & 1058 & 16.65 \\
\hline 6 & $30-31.5$ & $\begin{array}{c}\text { Drill } \\
\text { sampling }\end{array}$ & 3558 & 2837 & 79.74 & 599 & 16.84 & 122 & 3.43 \\
\hline 7 & $36-37.5$ & $\begin{array}{c}\text { Drill } \\
\text { sampling }\end{array}$ & 2335 & 1674 & 71.69 & 398 & 17.04 & 263 & 11.26 \\
\hline 8 & $15-16.5$ & $\begin{array}{c}\text { Drill } \\
\text { sampling }\end{array}$ & 1845 & 1231 & 66.72 & 290 & 15.72 & 324 & 17.56 \\
\hline 9 & $22.5-25$ & $\begin{array}{c}\text { Drill } \\
\text { sampling }\end{array}$ & 3342 & 2146 & 64.21 & 780 & 23.34 & 416 & 12.45 \\
\hline 10 & $30-31.5$ & $\begin{array}{c}\text { Drill } \\
\text { sampling }\end{array}$ & 2558 & 1734 & 67.79 & 509 & 19.90 & 315 & 12.31 \\
\hline 11 & $36-37.5$ & $\begin{array}{c}\text { Drill } \\
\text { sampling }\end{array}$ & 1927 & 1357 & 70.42 & 357 & 18.53 & 213 & 11.05 \\
\hline
\end{tabular}

(2) Initial velocity and desorption

The key of gas content method to predict coal and gas outburst is to determine the initial velocity of gas desorption and calculated the lost gas of coal seam [12].

To obtain accurate data must take out the coal sample and proceed the desorption experiment as soon as 
possible. Compared with the traditional sampling method, the main advantage of the integrative jumbo for deep hole sampling is that sampling and drilling at same time and also can realize fixed-point sampling, and the sampling time is only 1 to 2 minutes, this provided an effective technical method for confirming the lost gas of coal seam by greatly shorten the loss of time of coal samples before the desorption experiment and reduce the loss of gas providing effective technical means for confirming the lost gas of coal seam.

In the course of the experiment, we had a lot of underground desorption experiments for different depth of the coal samples, the desorption time was 30 minutes, in order to investigate the sampling effect of the integrative jumbo for deep hole sampling, desorption data obtained by this method was compared with the traditional sampling method, as shown in Figure 5 and Figure 6.

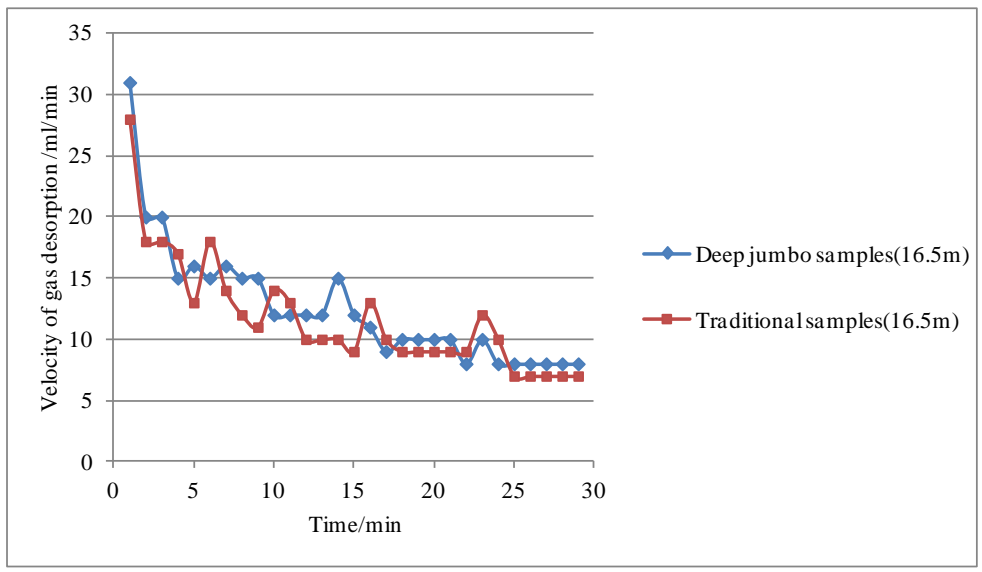

Figure 5 The desorption velocity of shallow hole sampling coal

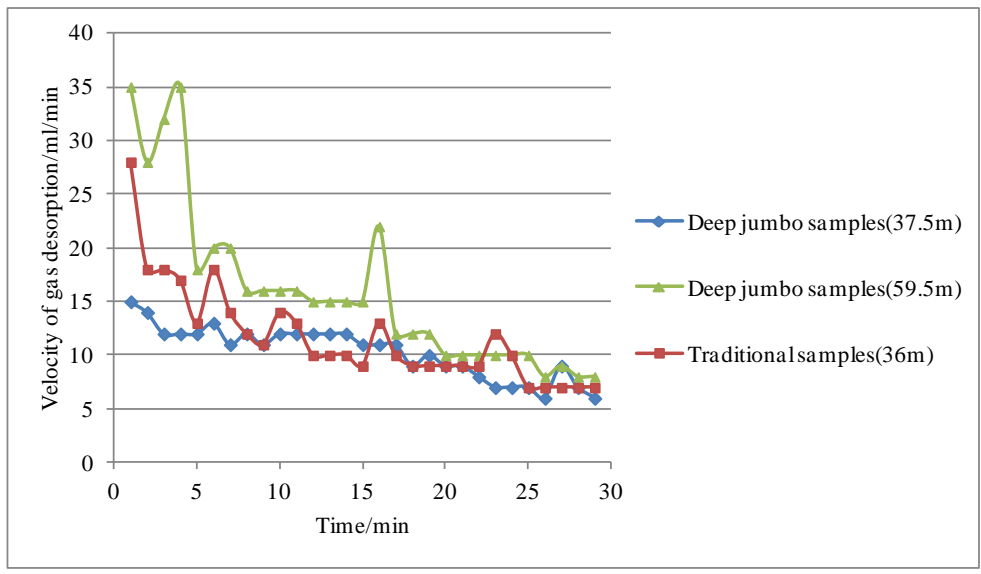

Figure 6 The desorption velocity of deep hole sampling coal

As we can see from Figure 5 and Figure 6, along with the increased of the depth of sampling, gas desorption has a tendency to gradually increase, this is consistent with the actual situation. According to the data of actual observation of mine pressure, usually about 15 meters on both sides of the roadway affected by stress change of scope, coal cracks resulted in some gas overflow, the measured gas content of coal seam is lower than that of the original content. At the same time, in the traditional sampling method, because of the long-time sampling, there was a large amount of gas loss and it lead to the measuring results of mine gas desorption being smaller. As we can see from Figure 5, in the same coal seam and the sampling depth is $16.5 \mathrm{~m}$ at the same time, the coal sample gas desorption speed especially initial speed taken by the integrative jumbo for deep hole sampling is 
faster than traditional sampling method, but because of the sampling distance is short, the sampling time is short, the coal sample desorption results taken by those two sampling methods had little difference.

As we can see from Figure 6, the sampling depth and gas desorption of the integrative jumbo for deep hole sampling are larger than the traditional sampling method, the difference is bigger especially in the initial desorption rate, this is because as the increase of sampling depth, the sampling time of traditional sampling method prolonged, resulting in the loss of coal gas desorption increased, the test data can't reflect the actual gas desorption speed of the coal seam and affect the calculation accuracy of the initial amount of gas loss.

\section{Conclusion}

According to the fact that the coal seam in our country is soft and the traditional sampling equipment is difficult to achieve the required sampling depth, speed, integrity and so on, integrative jumbo for deep hole sampling is designed and built, this jumbo has the properties of large power and small volume, can realize lateral and distant drilling through obstacle, it also has functions of automatic locking position with highly reliable lubrication system. The field test for integrative jumbo showed that:

(1) The integrative jumbo for deep hole sampling achieved Fixed-point sampling and sampling while drilling, the real sampling time of integrative jumbo is just 1 to 2 minutes, providing effective technical means for confirming the lost gas of coal seam.

(2) The total weight of coal samples obtained by the test is generally higher than $1000 \mathrm{~g}$, the maximum weight of coal samples obtained when the coal drilling depth was 25, the weight of coal sample is $6353 \mathrm{~g}$; also the weight of coal samples with greater than $1 \mathrm{~mm}$ diameter exceed $500 \mathrm{~g}$, and to a maximum of $2690 \mathrm{~g}$. Completely meet the needs of the experimental determination of gas.

(3) Along with the increased of the depth of sampling, gas desorption has a tendency to gradually increase, resulting the loss of coal samples in the gas desorption increased, the measured data can not reflect the actual coal seam gas desorption rate, the sampling depth and gas desorption of the integrative jumbo for deep hole sampling are larger than the traditional sampling method, completely meet the accuracy of the initial amount of gas loss.

\section{Acknowledgment}

This work was supported by National Natural Science Foundation Project (51304128), Scientific Research Foundation of Shandong University of Science and Technology for Recruited Talents (2013RCJJ049), Open Project of State Key Laboratory Breeding Base for Mining Disaster Prevention and Control(Shandong University of Science and Technology) (MDPC2012KF10), China Postdoctoral Science Foundation (2013M541942), Shandong Provincial Natural Science Foundation, China (ZR2013EEQ015), Specialized Research Fund for the Doctoral Program of Higher Education (20133718120013). The authors gratefully acknowledge them for financial support of this work.

\section{References}

[1] WANG Gang. "Study on Prediction of Coal and Gas Outburst by Gas Content", Shandong University of Science and Technology, 2012.

[2] HU Qian-ting, ZOU Yin-hui, WEN Guang-cai, et al. "New technology of outburst danger prediction by gas content", Journal of china coal society, Pp276- 280, 2007.

[3] YUAN Liang, XUE Sheng, XIE Jun. "Study and Application of Gas Content to Prediction of Coal and Gas Outburst”, Coal Science and Technology, Pp47- 51, 2011.

[4] QI Li-ming. "Research on the Measuring Gas Content Technology of Stress-releasing and Sealed Coal Core”, China University of Geosciences, 2011.

[5] WANG Wei-hua. "Research on the Gas Content Determination Method and the Gas Content Index 
Critical Value of Regional Prediction in the $\mathrm{B}_{1}$ Coal Bed of Yu Xi”, Henan Polytechnic University, 2011.

[6] WANG Yao-feng. "For coal cuttings exposure time was measured using the sampling orifice gas content to explore”, coal mine safety, Pp39- 40, 2005.

[7] LIU Li-yang, LI Chao. "Application of Vacuum Ejector in Automatic Equipment", Mechanical Engineer, Pp142- 143, 2009.

[8] PAN Xiao-bin, LI Xiao-ning, XU You-xiong. "Energy Saving Pneumatic Piston Vacuum Generator", China Mechanical Engineering, Pp1300- 1325, 2009.

[9] PAN Xiao-bin. "Research and Development on New Type of Energy Saving Pneumatic Piston Vacuum Generator", Nanjing University of Science and Technology, 2008.

[10] YU Bu-fan, WANG You-an. "Mine gas disaster prevention and Utilization Technology Handbook", China Coal Industry Publishing House, 2000.

[11] The standard of the Ministry of the people's Republic of China Coal Industry. Coal seam gas content and composition determination (desorption) (MT77-84) China Coal Industry Publishing House, 1983.

[12] Kissell. F.N. Meculloch. The Direct Method of Determining Methane Content of Coal beds for Ventilation Design[R]. U.S.Bureau of Mines Report of Investigation, 1973. 